\title{
Indicaciones restrictivas y anestesia
}

\author{
GERMÁN ZEGERS M. ${ }^{1}$
}

\begin{abstract}
Anesthesiologists may deal with ethical dilemmas when looking after Not To Be Resuscitated (NTBR) patients. Sometimes the latters are scheduled to undergo surgical procedures that are palliative in nature. With the advent of the cardiopulmonary resuscitation in the 1960 s, new problems arose, such as long resuscitations, quality of life impairment and unnecessary protracted agony. Besides the fear to death and suffering, resuscitation's dread appeared. In the beginning, the decisión to reject the resuscitation was the physician's responsability. The development of the Patient Self-Determination Act (PSDA) transfered to the patient or to his/her legal surrogates the right to decide about his/her medical treatment, specially at the end of life. This article revised the evolution that allowed to exercise the patient autonomy, as well as the best way to proceed when anesthesia and surgery are necessary to care for a patient with a Do Not Resuscitate Order.
\end{abstract}

\section{RESUMEN}

El anestesiólogo puede enfrentar dilemas éticos cuando debe anestesiar pacientes con indicaciones restrictivas (Límite del Esfuerzo Terapéutico, Orden de No Reanimar). Estos pacientes con frecuencia son sometidos a intervenciones destinadas a mejorar su calidad de vida, o para el control de síntomas, a pesar de tener un mal pronóstico evolutivo, y/o deterioro de su condición física. A mediados de la década de 1960, con la RCP (Reanimación Cardiopulmonar) aparecieron nuevos problemas, como reanimaciones reiteradas, deterioro de la calidad de vida, y prolongación de la agonía. Entonces, al miedo a la muerte y al sufrimiento, se sumó el miedo a la reanimación. Inicialmente, el médico responsable del paciente era el único habilitado para rechazar estas medidas de reanimación (NTBR, "not to be resuscitated"), con el subsiguiente debate bioético. Mas tarde, el desarrollo del principio de autonomía, transfirió al paciente y a su entorno más cercano el derecho a tomar decisiones informadas sobre su propio tratamiento médico ${ }^{1}$. Este artículo revisa los antecedentes relevantes que han permitido el traspaso del poder de decisión a los pacientes, así como la mejor forma de proceder ante la necesidad de administrarles anestesia cuando hay indicaciones restrictivas.
Key words: Bioethical Issues, Patient Rights, Advance Directive Adherence.

Palabras clave: Bioética, Derechos del paciente, Órdenes de No Resuscitar.

Anestesiólogo, Curso Bianual de Expertos en Dolor AARBA, GAFOS en Cuidados Paliativos.

Unidad de Cuidados Paliativos. Clínica Dávila.

El autor declara no tener conflictos de intereses, en relación a este artículo. 


\section{Introducción}

E n décadas recientes, los principios de bioética han modificado considerablemente las prácticas clínicas, dejando atrás una visión paternalista de la medicina, basada en el beneficio inmediato del paciente. Ahora, ellos pueden y deben tomar sus propias decisiones de manera informada, optando entre las distintas alternativas de tratamiento propuestas por sus médicos ${ }^{2}$. Sin embargo, el problema surge cada vez que estos principios se contraponen entre sí, o cuando existe un conflicto entre la voluntad del paciente, y la interpretación que hace de ellos el equipo de salud encargado de administrarla. Y esto no es ajeno al pabellón quirúrgico, ni mucho menos al ejercicio de la anestesiología.

Otros factores, como los demográficos y culturales: el envejecimiento de la población, la disponibilidad de nuevos y costosos recursos terapéuticos, y la negación de la muerte por parte de una sociedad altamente tecnificada, contribuyen a hacer cada vez más frecuentes los dilemas éticos al final de la vida.

Pacientes con enfermedades terminales (ancianos, adultos y niños), o con una calidad de vida progresiva e irreversiblemente deteriorada, que hayan declarado (ellos o sus representantes) expresamente su voluntad de poner un Límite al Esfuerzo Terapéutico (LET), o después de haber suscrito una Orden de No Reanimar (ONR), pueden requerir anestesia para procedimientos quirúrgicos destinados a aliviar su sufrimiento, o a subsanar problemas de salud puntuales, sin que esto sea necesariamente una contradicción ${ }^{3}$. Para garantizar el derecho a elegir de un paciente, no podemos conformarnos con aplicar la ley del todo o nada. Junto a él y sus familiares cercanos, debemos ser capaces de ofrecer las opciones reales que más se acerquen al cumplimiento de su voluntad. Una elección donde no hay opciones, no es una elección 4 .

\section{Dilema Ético}

Los procedimientos que requieren anestesia para pacientes con decisiones restrictivas (ONR, LET), suelen corresponder a medidas de soporte consideradas proporcionadas por parte del paciente (v.g. sondas de alimentación, accesos vasculares), cirugías de urgencia con altas probabilidades de éxito, no relacionadas con la enfermedad terminal, cirugías de urgencia para una complicación subsanable de la enfermedad de base, o intervenciones para el alivio del dolor y otros síntomas ${ }^{3}$.

Los argumentos a veces esgrimidos por los anes- tesiólogos para negarse a brindar anestesia a un paciente con decisiones restrictivas, suelen ser:

a) Los elementos constitutivos de una anestesia son muy similares a los de una Reanimación Cardiopulmonar (RCP), como: administración de oxígeno, accesos vasculares, intubación de la tráquea, asistencia ventilatoria, reposición de volumen, uso de drogas vasoactivas. Por lo tanto, no podemos dar anestesia sin transgredir la voluntad declarada del paciente, que es, no realizar RCP3.

b) Los cambios fisiológicos ocasionados por la anestesia y el procedimiento quirúrgico, en el contexto de un paciente con enfermedad terminal, o con condición física gravemente comprometida, pueden desencadenar un paro cardiorrespiratorio. Al estar nosotros impedidos, por mandato del paciente, de realizar RCP, estaríamos incurriendo en una forma encubierta de eutanasia, o al menos de muerte asistida ${ }^{4}$.

c) Al realizar un procedimiento médico activo que pudiera prolongar innecesariamente la agonía, causar dolor o sufrimiento, o empeorar aún más la calidad de vida del paciente, podríamos estar contraviniendo su manifiesto deseo de limitar el esfuerzo terapéutico, contribuyendo a negarle una muerte digna ${ }^{5}$.

Por el contrario, los derechos que asisten al paciente a recibir anestesia para un procedimiento puntual, a pesar de tener suscrita una ONR son: el derecho a la vida, el derecho a recibir asistencia médica proporcional, y especialmente, el principio bioético de la autodeterminación ${ }^{6}$.

Ante el requerimiento de anestesia para un paciente terminal, o con deterioro severo de su calidad de vida, que haya suscrito una ONR, el anestesiólogo podrá legítimamente declarar su objeción de consciencia ${ }^{4}$, sólo después de haber hecho un exhaustivo análisis de las implicancias bioéticas del problema, para luego ofrecer alternativas reales y oportunas a esta decisión, como delegar el caso a un colega competente y asequible, que esté dispuesto a proceder, o ser capaz de ofrecerle una opción terapéutica distinta que no requiera anestesia.

\section{Antecedentes}

Existen guías tanto de la ASA, como del Reino Unido y Canadá ${ }^{7-8-9}$ para enfrentar este dilema, basadas en conceptos fundamentales:

I. Principios de Bioética postulados por Beauchamp 
y Childress ${ }^{2}$.

Autonomía. Prioritario sobre los demás, se refiere al respeto de las capacidades de toma de decisiones del individuo, permitiéndole elegir entre sus distintas opciones de salud.

Beneficencia. En forma general, favorecer al paciente.

No maleficencia. Evitar el causar daño.

Justicia. Distribución equitativa de los beneficios a todos los pacientes.

II. Paro Cardiorrespiratorio (PCR). Es imprescindible diferenciar qué tipo de PCR vamos a reanimar. La tasa de éxito de RCP para un paro del peri operatorio, es mucho mayor que la del paro espontáneo en el ambiente hospitalario general $(92 \% \text { vs } 14 \%)^{10}$. Las decisiones restrictivas históricamente surgieron debido a las bajas tasas de sobrevida, o a la alta probabilidad de adquirir graves secuelas neurológicas con deterioro de la calidad de vida, luego de una RCP en la comunidad o en el ambiente hospitalario general. No es razonable suscribir una ONR para un tipo de PCR, basándose en los malos resultados de otro. La indicación de iniciar RCP, o la orden de no hacerlo, debe tomar en cuenta este hecho indesmentible.

III. Reanimación Cardiopulmonar (RCP). Cuando un paciente rechaza los procedimientos que son Comunes a la anestesia y la RCP, no puede recibir anestesia. Al enfrentar a un paciente con decisiones restrictivas que va a ser sometido a anestesia, las opciones no se limitan exclusivamente a reanimación total, o no reanimación. Existen varias alternativas de RCP3:

a) Reanimación total. Difícil de implementar, sin el riesgo de transgredir la voluntad de un paciente con decisiones restrictivas.

b) Reanimación dirigida a objetivo. En la que el juicio del equipo médico determina cuán lejos llegar, y qué decisiones restrictivas aplicar, tomando en cuenta los deseos del paciente (v.g. "acepto la cirugía, pero no quiero someterme a ventilación mecánica en cuidados intensivos").

c) Reanimación dirigida al procedimiento. Donde el paciente manifiesta qué procedimientos de reanimación permite realizar, y cuáles de las decisiones restrictivas se deberán mantener vigentes (v.g. "permito el uso de oxígeno y drogas vaso activas, pero no quiero masaje ni desfibrilación cardíacas").

IV. Orden de No Reanimar (ONR). Con anterioridad a la aparición de las guías clínicas, las ONR eran automáticamente suspendidas antes de la cirugía ${ }^{3-4-11}$, para permitir al anestesiólogo cumplir con los principios éticos de beneficencia y no maleficencia. Sin embargo, este proceder a veces se oponía al derecho prioritario de la autodeterminación del paciente. Actualmente, se acepta que la ONR implica estrictamente no realizar RCP, entendiendo por ello masaje cardíaco y desfibrilación ventricular, excluyendo todos los demás elementos de una anestesia. Por lo tanto, los medios habituales de una anestesia no son $\mathrm{RCP}^{7-8-9}$.

Es probable que al momento de suscribir una ONR, no se haya discutido específicamente la posibilidad de requerir anestesia para un procedimiento compatible con los intereses del paciente. En ese caso, se debe replantear la validez de la ONR. Cuando el paciente tiene comprometidas sus facultades mentales, los familiares cercanos deben ponderar si el procedimiento es proporcional a la voluntad manifestada por el paciente, a pesar de tener una ONR pre existente.

La ONR se limita exclusivamente a la no realización de RCP, y de ninguna manera implica la restricción de otros cuidados a los que el paciente tenga derecho ${ }^{12}$. La ONR no es definitiva ni permanente, y el paciente o sus familiares cercanos pueden en cualquier momento revertirlas con libertad ${ }^{13}$.

V. Limitación del Esfuerzo Terapéutico (LET). Consiste en no aplicar medidas desproporcionadas con fines terapéuticos en pacientes con mal pronóstico vital y/o mala calidad de vida. Son concordantes con las buenas prácticas clínicas, cuando se alinean con las decisiones restrictivas del paciente. Pero debemos recordar que el LET es un instrumento supeditado al principio de autodeterminación, y será el paciente o sus familiares cercanos quienes decidan cómo y cuándo proceder. Al igual que la ONR, el LET es también reversible. Los aspectos del LET más controvertidos, son aquellos casos en que se plantea retirar algún tipo de tratamiento, en lugar de implementarlos. Un ejemplo de ello, es la necesidad de mantener ventilación mecánica no programada luego de una anestesia. En tal situación, serán los familiares cercanos, el equipo médico tratante, y el comité de ética de la institución, junto al anestesiólogo encargado del caso, quienes tomen la decisión ${ }^{14}$.

\section{Realidad nacional}

No existe en nuestro país una normativa legal específica que señale la manera de actuar frente a este potencial dilema. Abordado escasamente en la literatura clínica nacional, se sugiere reconsiderar la ONR antes de entrar a pabellón, analizando las situaciones 
y procedimientos aceptados o rechazados por el paciente ${ }^{11}$, para "llegar a un consenso previo"15.

Nuestra legislación contempla, a través de la Ley 20.584 de Derechos y Deberes del Paciente, el derecho a "Tener información oportuna y comprensible de su estado de salud", y a "Aceptar o rechazar cualquier tratamiento". La Ley no hace referencias a indicaciones restrictivas específicas, pero sí enfatiza la obligatoriedad del Consentimiento Informado para realizar cualquier procedimiento ${ }^{16}$.

\section{Casos clínicos}

Los siguientes casos son reales, y han sido modificados sólo con la intención de servir de mejor ejemplo. La explicación que se hace de ellos es de exclusiva responsabilidad del autor y por lo tanto, pueden tener interpretaciones discrepantes.

Caso 1. Paciente masculino de 53 años, con diagnóstico de Cáncer de Colon en etapa IV. Suscribió ONR y LET. Presenta dolor abdominal refractario a tratamiento, con patrón colestásico de pruebas hepáticas que sugiere obstrucción de las vías biliares. No toleró la Colangio Resonancia Magnética, y la ecografía no es concluyente. Se plantea una Colangiografía Endoscópica Retrógrada con eventual instalación de Stent biliar bajo anestesia, para aliviar su dolor. El anestesiólogo duda ante el impedimento de realizar RCP, y la contradicción entre LET y la indicación del procedimiento. Finalmente se aplica un Stent biliar obteniendo alivio significativo del dolor. El paciente fallece en su domicilio dos semanas después.

Consideraciones éticas. Al firmar el LET no se discutió la posibilidad de requerir un procedimiento terapéutico para el alivio del dolor. La ONR no contemplaba una RCP intra operatoria, por lo tanto, se acordó permitir una RCP dirigida a procedimiento (no masajear, no desfibrilar). El objetivo, la intención y la acción del procedimiento pretendían el alivio del dolor, justificando el potencial daño. El paciente suscribió un Consentimiento Informado, validando su derecho a la autodeterminación.
Caso 2. Hombre de 65 años con Cáncer de Próstata etapa IV, Karnofsky 40. Cursando hidronefrosis y pielonefritis crónica con compromiso general, causada por recidivas locales y radioterapia. Programado para ureteroscopía e instalación de catéter doble jota, con ONR suscrito. El paciente no acepta el riesgo de ventilación mecánica prolongada ante una eventual descompensación peri operatoria. El anestesista se niega a proceder, pero contacta al radiólogo intervencionista, y en acuerdo con el equipo tratante, se realiza una pielotomía bajo TAC con anestesia local.

Consideraciones éticas. No se puede realizar una anestesia, si el paciente no acepta los riesgos implícitos en ella. Siempre se debe buscar el mejor interés del paciente.

\section{Discusión}

La mejor forma de resolver un eventual conflicto entre la posición ética del anestesista y la autonomía del paciente, es mediante la comunicación abierta e informada entre el paciente, sus familiares cercanos, y el equipo médico tratante, en términos de transparencia y respeto mutuos. En lo posible, esto debe ocurrir antes de que el paciente pierda sus capacidades cognitivas, dejando registradas las decisiones acordadas en un documento clínico.

Al momento de tomar decisiones anestésicas o quirúrgicas, en el caso de que el paciente o sus familiares cercanos no puedan hacerlo, el equipo médico tratante deberá dar a conocer y representar los deseos del paciente ante el comité de ética.

Al enfrentar el dilema de tener que prestar asistencia médica con riesgo de causar daño, se debe tener en cuenta el principio de doble efecto, esto es: el objetivo, la intención y la acción planteadas deben ser beneficiosas, el daño potencial no es el deseado pero se tolera, y el fin que se persigue debe ser tan importante como para justificar el riesgo. No existen directrices corporativas ni legislación nacional que nos oriente, por tanto, cada servicio debe acordar su propia forma de proceder, tomando en cuenta el Lex Artis y los mejores intereses del paciente. 


\section{Referencias}

1. Ruiz García J. Tesis Doctoral. Orden de no reanimar la final de la vida en el paciente cardiológico. Madrid: Facultad de Medicina Universidad Complutense; 2015.

2. Beauchamp TL, Childress JF. Principles of Biomedical Ethics. 5th ed. Oxford: Oxford University Press; 2001.

3. McBrien ME, Heyburn G. "Do nor attempt resuscitation" orders in the peri-operative period. Anesthesia. 2006. June; 61 7:625-627.

4. Gempeler-Rueda FE, BrigardPérez AM. Órdenes de No Reanimar y Anestesia. Revista Colombiana de Anestesiología. 2016;44(2):146-50.

5. Borsellino P. Limitation of the therapeutic effort: ethical and legal justification for withholding and/or withdrawing life sustaining treatments. Multidiscip Respir Med 2015 Feb;10(1):5.
6. Summaries of the Reports for the President's Commission for the Study of Ethical Problems in Medicine and Biomedical and Behavioral Research. Making Health Care Cecisions. 1982.

7. American Society of Anesthesiologists. Ethical guidelines for the anesthesia care of patients with do-not-resuscitate orders or other directives that limit treatment. Updated October 16 2013.

8. The Association fo Anaesthetists fo Great Britain and Ireland. Do Not Resuscitation (DNAR) Decisions in the Perioperative Period. May 2009.

9. Canadian Anesthesiologists' Society Committee on Ethics. 2002. Peri-operative status of "do not resuscitate" (DNR) orders and other directives regarding tratment. (consultado noviembre de 2015).

10. Angus DC. Successful rsuscitation from in-hospital cardiac arrest- What happens next? JAMA 2015 Sep;314(12):1238-
9.

11. Cereceda L. Orden de No Reanimar, consideraciones sobre este problema. Rev Med Clin Las Condes 2011;22(3):369-76.

12. Koch KA. Allow natural death: "Do Not Resuscitate" Orders. Northeast Florida Medicine 2008 Jan; Supplement.:13-7.

13. Grupo de estudios de Ética Clínica de la Sociedad Médica de Santiago. La reanimación cardiorespiratoria y la orden de no reanimar. Rev Med Chil 2007;135:669-79.

14. Herreris B, Palacios G, Pacheco $E$. Limitation of the therapeutic effort. Rev Clin Esp. 2012;212:134-40 - Vol. 212 Núm.3

15. Sumrall WD, Mahanna E, Sabharwal V, Marshall T. Do Not Resuscitate, Anesthesia, and Perioperative Care: A Not So Clear Order. Ochsner J 2016;16(2):176-9.

16. Ley 20.584 de Derechos y Deberes de los Pacientes. Ministerio de Salud de Chile. Abril 2012. 